\title{
Computational Study of the Chemistry of 3-Phenylpropyl Radicals
}

\author{
James D. Modglin, II, Jason C. Dunham, ${ }^{\dagger}$ Chad W. Gibson, ${ }^{\dagger}$ Ching Yeh Lin, ${ }^{\ddagger}$ Michelle L Coote, ${ }^{\ddagger}$ and
} James S. Poole P $^{*,+}$

\author{
${ }^{+}$Department of Chemistry, Ball State University, Muncie, Indiana 47306, United States \\ ${ }^{\ddagger}$ ARC Centre for Excellence for Free Radical Chemistry and Biotechnology, Research School of Chemistry, Australian National University, \\ Canberra ACT 0200, Australia
}

S Supporting Information

ABSTRACT: Density functional theory (DFT) and G3-type (G3(MP2)-RAD) composite calculations were performed on a series of substituted 3-phenylpropyl radicals, to determine the relative importance of fragmentation and cyclization reactions in the chemistry of such species. Our studies indicate that
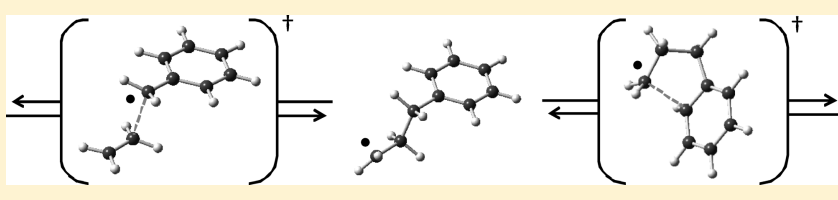
cyclization is generally the more important of these reactions, with exceptions where fragmentation yields highly stabilized benzylic species. The energetic barriers for the cyclization reactions (enthalpies of activation) were found to be determined largely by the stability of the reactant radical and to a lesser but significant extent, by steric factors. Polarity effects in the transition state (modeled by SOMO-LUMO gaps of the products) appear to be less important. The data obtained indicated that the addition of benzyl radical to alkenes may be considered to be irreversible, but calculations for $\alpha$-substituted styrenic systems indicate that reversibility of addition may become a factor in dilute polymerizing solutions for select systems.

\section{INTRODUCTION}

The kinetics of addition of benzyl and cumyl radicals to alkenes, generating substituted 3-phenylpropyl systems has been studied in detail by Fischer and co-workers, ${ }^{1,2}$ and the results were interpreted in terms of frontier orbital models utilized to describe the importance of polar effects in the interplay of steric, polar, and thermodynamic effects that occur in the addition of free radicals to unsaturated systems. The data for benzyl and cumyl radicals may be used as useful models for the kinetics of free-radical homo- and copolymerization of styrenic monomers. It is generally accepted that in a polymerizing system, the formed 3-phenylpropyl radical will add to another monomer (the choice of which is dictated by terminal or penultimate unit reactivity ratios) to extend the growing chain.

The fate of substituted 3-phenylpropyl radicals (and heteroanalogues) in the absence of viable monomers, or in dilute solutions of same has been less extensively investigated. Gasanov et al., in an EPR-based study, measured the rate of $\beta$-fragmentation of 3-phenylpropyl systems to their constituent benzyl and alkene fragments. ${ }^{3}$ The measured rate coefficients for fragmentation, $k_{\beta}$ at $298 \mathrm{~K}$ were $10^{2}-10^{4} \mathrm{~s}^{-1}$ (depending on substitution), which under some circumstances may be sufficiently fast to compete with addition rates, even in bulk monomer concentrations (ca. $10 \mathrm{~mol} \mathrm{~L}^{-1}$ ), where $k_{\text {add }}$ ranges from $10^{1}$ to $10^{5} \mathrm{M}^{-1} \mathrm{~s}^{-1}$ (measured by laser flash photolysis, and dependent on substitution of the benzyl radical and olefin). ${ }^{1}$ In addition, the fragmentation of 2-phenoxyethyl systems has been investigated as a model for decomposition of humic materials. ${ }^{4}$

An alternative fate for these types of radicals (Scheme 1) involves their cyclization onto the aryl ring to generate cyclohexadienyl radicals. Long considered to be unfavorable reactions due to the concomitant loss of aromaticity, such reactions, in conjunction with rearomatization with a suitable oxidizing species, have been found to have synthetic applicability. Cyclization onto pyrroles, ${ }^{5}$ furans, ${ }^{6}$ and pyridines ${ }^{7}$ by alkyl radicals have been observed, along with cyclization onto benzene rings to generate both 5- and 6-membered rings. ${ }^{8-10}$ Cyclization with aryl radicals onto arene rings has also been reported. ${ }^{11}$ The group of Zard ${ }^{6-10}$ has utilized xanthates as radical precursors, along with peroxides as oxidants to generate bicyclic derivatives. Alternative methods have utilized aminoxyl radicals as oxidants. ${ }^{11,12}$ The latter approach has the advantage that cyclization may be driven to high yields due to the reversible coupling of aminoxyl species with carbon-centered radicals. Such an aminoxyl-mediated oxidation may also be conceivable in quasi-living radical polymerizations.

Much of the cyclization reactions reported involve heteroanalogues of simple 3-phenylpropyl systems, often including amide or sulfonamide functionalities within the cyclizing alkyl chain. Attempts to cyclize 1,3-disubstituted 3-phenylpropyl radicals or 2-phenoxyethyl radicals proceeded in poor to moderate yields, ${ }^{8 a}$ depending on the nature of the substituents used. Presumably $\beta$-fragmentation is a competing reaction in these cases-certainly the product isolated from attempted cyclization of the phenoxy analogue is a $\beta$-fragmentation product.

Thus, we have performed a computational study on variously monosubstituted 3-phenylpropyl systems (and some heteroanalogues), with the intent of elucidating the major structurereactivity relationships for fragmentation and cyclization reactions. The substituents were chosen to reflect a broad range of functionality (Scheme 2). The aim of this study is 2-fold:

\footnotetext{
Received: December 24, 2010

Revised: February 6, 2011

Published: February 28, 2011
} 
Scheme 1. Generation and Potential Fates of 3-Phenylpropyl Radicals<smiles>[X]C=C</smiles>

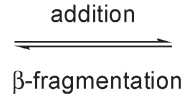

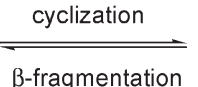

$\beta$-fragmentation
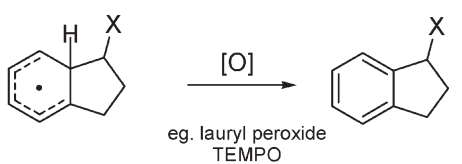<smiles>[Y]/C=C\CCCCCO</smiles><smiles>[X]CCC([X])CCc1ccccc1</smiles>

polymer

Scheme 2. Substituted 3-Phenylpropyl Radicals and Analogues Used in This Study<smiles>CCCCc1ccccc1</smiles>

$(1 \mathrm{a}-\mathrm{g})$

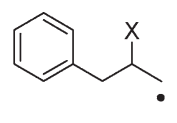

$(2 b-g)$

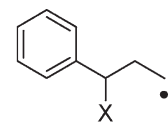

$(3 \mathrm{~b}-\mathrm{g})$

\begin{tabular}{|lll}
$\mathbf{a} X=\mathrm{H}$ & $\mathbf{b} X=\mathrm{CH}_{3}$ & $\mathbf{c X}=\mathrm{F}$ \\
$\mathbf{d X}=\mathrm{OCH}_{3}$ & eX $=\mathrm{CN}$ & $\mathbf{f X}=\mathrm{CH}=\mathrm{CH}_{2}$ \\
$\mathbf{g} \mathrm{X}=\mathrm{C}_{6} \mathrm{H}_{5}$ & & \\
\hline
\end{tabular}

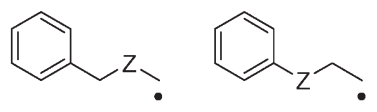

$(4 \mathrm{~h}-\mathrm{j})$

$(5 \mathrm{~h}-\mathbf{j})$

- To determine the degree to which 3-phenylpropyl systems will undergo $\beta$-fragmentation, and to determine whether $\beta$-fragmentation is sufficiently rapid in certain cases to the point where the reversibility of radical addition plays a significant role in polymerizing systems, and second

- To determine the extent of the synthetic utility of cyclization/oxidation sequence for conversion of 3-phenylpropyl radicals into substituted indanes, and whether future kinetic studies of $\beta$-fragmentation reactions need to consider indanes as significant contributors to any product distributions.

We report the findings of our study herein.

\section{THEORETICAL MODELS}

Energies. A large body of work has been published out of the Radom group regarding the evaluation of theoretical models for free radical energies and reaction thermodynamics. ${ }^{13-16}$ Geometry optimizations, single point energies and frequency calculations were carried out using the GAUSSIAN 03 program suite. ${ }^{17}$ Calculated vibrational zero-point energies, and enthalpic corrections $\left(\Delta H_{\text {vib }}\right)$ at the B3LYP/6-31G(d) level of theory ${ }^{18}$ were scaled using the scaling factors recommended by Scott and Radom. ${ }^{19}$ All optimized stationary points were found to have the appropriate number of imaginary frequencies, and in the case of transition states the imaginary modes corresponded to the correct reaction coordinates. Spin contamination at the B3LYP/

6-31G(d) level of theory is significant in some cases, but not necessarily substantial. Typical values for the spin expectation value $\left\langle S^{2}\right\rangle$ ranged between 0.75 and 0.80 at this level of theory, with greater spin contamination in the transition state geometries than in minima. It is noted that energy refinements at G3(MP2)$\mathrm{RAD}$ use restricted open-shell wave functions for all component energy calculations (see below).

Whereas B3-LYP/6-31G(d) is usually sufficiently accurate for geometry optimizations and frequency calculations for these types of reaction, ${ }^{13-16}$ the energies calculated at this level of theory have significant deviation with respect to the available experimental data. ${ }^{20}$ Improved energies were therefore calculated using the G3(MP2)-RAD composite method ${ }^{21}$ in order to achieve higher levels of accuracy. This method approximates $\operatorname{URCCSD}(\mathrm{T})$ calculations with the large triple- $\zeta$ basis set GTMP2large as the sum of the URCCSD(T)/6-31G(d) level energies and a basis set correction term evaluated at the $\mathrm{R}(\mathrm{O}) \mathrm{MP} 2$ level of theory. This method has been shown to deliver "chemical accuracy" (ca. $1 \mathrm{kcal} / \mathrm{mol}$ ) when assessed against a large test set of experimental thermochemical data, ${ }^{21}$ and has recently been shown to deliver similar performance for a large test set of bond dissociation energies and associated radical stabilization energies for carbon-centered radicals. ${ }^{22}$ For the specific case of radical addition to $\mathrm{C}=\mathrm{C}$ double bonds, and the corresponding $\beta$-scission processes, G3(MP2)-RAD was recently found to reproduce higher-level W1 calculations to within chemical accuracy, ${ }^{16,23}$ and has been used successfully to reproduce experimental propagation rate coefficients in several freeradical polymerization processes. ${ }^{24}$

Rate coefficients for reaction at temperature $T, k(T)$ were estimated in the range $298-353 \mathrm{~K}$ using transition state theory;

$$
k(T)=\frac{k_{\mathrm{B}} T}{h}\left(c^{\circ}\right)^{1-m} \mathrm{e}^{\left(-\Delta G^{\ddagger} / R T\right)}
$$

where $k_{\mathrm{B}}$ and $h$ are Boltzmann's and Planck's constants respectively, $R$ the ideal gas constant, $m$ the molecularity of the reaction (in the case of cyclization and fragmentation reactions unimolecular, bimolecular for addition reactions), and $\Delta G^{\ddagger}$ is the free energy of activation for reaction. The concentration factor $c^{\circ}$ converts the gas-phase $\Delta G^{\neq}$from the standard state of $1 \mathrm{~mol}$ of ideal gas at the specified temperature and pressure $(P$ at $1 \mathrm{~atm})$ to standard concentration units of $\mathrm{mol} \mathrm{L}^{-1}$ and is equal to $c^{\circ}=P$ / $R T$. Equation 1 also typically includes a tunneling correction: given that all of the above reactions may considered in terms of an attack of a radical species with spin density on a heavy atom ( C, N, O, or S) on a similarly heavy atom involved in a double 
Fragmentation TS
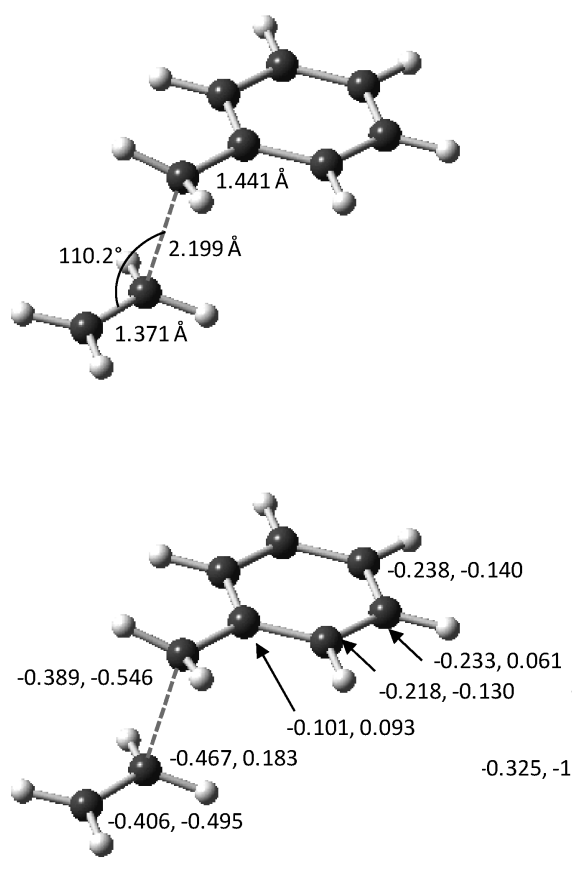

3-Phenylpropyl radical

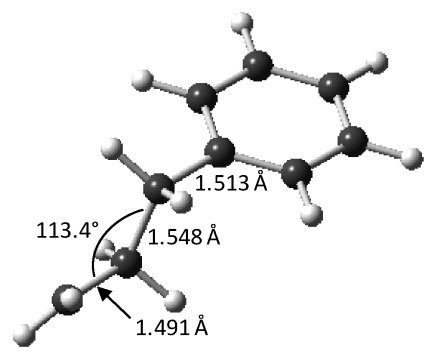

Cyclization TS
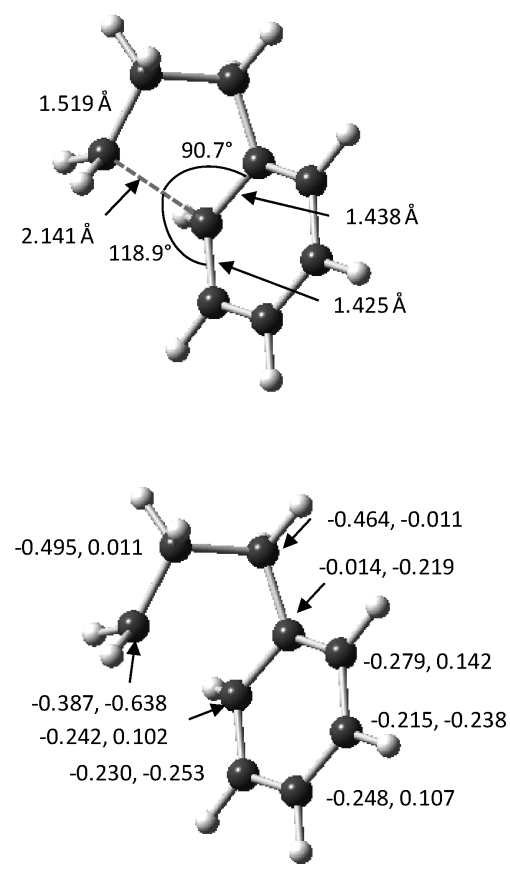

Figure 1. Optimized geometries and natural population analysis (NPA) charge and spin densities calculated at the B3LYP/6-31G* level of theory for 3-phenylpropyl radical, and its fragmentation and cyclization transition states. Charge densities are listed first, spin densities second. Charge and spin densities for hydrogen atoms are not shown, but in all cases, charge densities vary between +0.20 and +0.26 and spin densities between -0.06 and +0.03 for hydrogen atoms.

bond, we assume that such a correction will have minimal effect on the kinetics of reaction. Parameters such as enthalpies and entropies of activation $\left(\Delta H^{\ddagger}\right.$ and $\left.\Delta S^{\ddagger}\right)$, and the Arrhenius parameters $E_{\mathrm{A}}$ and $A$ for reaction were determined from interpolation of $k(T)$ between 298 and $353 \mathrm{~K}$. Enthalpies and entropies of reaction $\left(\Delta H_{R}\right.$ and $\left.\Delta S_{R}\right)$ were determined from calculated free energies in a similar manner.

As an initial approximation, enthalpies, entropies and free energies for each species in the gas phase were calculated from standard harmonic oscillator and rigid rotor partition functions. ${ }^{24}$ It is noted from previously published work that the treatment of low frequency torsional modes as harmonic oscillators leads to a degree of inaccuracy in calculated rate coefficients, manifested primarily in the interpolated Arrhenius pre-exponential. $^{25}$ To address this problem, the low frequency torsional modes were instead treated as hindered internal rotations using Truhlar's CT-C $\omega$ method. ${ }^{26}$ This method has been shown to provide the most cost-effective performance $^{25}$ and is implemented in GAUSSIAN 03. There are a number of low frequency modes in the cyclized products and cyclization transition states that may be described as torsional (or pseudorotational) modes. A full 1-dimensional rotational potential cannot be constructed for these species without bond rupture; and therefore no hindered rotor corrections may be readily applied to these species. It is noted that there is in fact a distribution of potential rotamers of the 3-phenylpropyl radical that contribute to the overall energetics of the system. Typically in a thermochemical calculation, the combined effect of these rotamers is small, since the rotamers that are close in energy to the minimum energy structure will dominate the Boltzmann distribution. However, this does not necessarily hold for kinetics (particularly where a number of rotational degrees of freedom become locked in the transition state). Therefore, we make the additional assumption that the energy differences of the lowlying conformers are preserved in their respective transition states, and this should apply to good approximation where the conformers correspond to rotations of bonds not directly associated with the reactive center.

Free energies of solvation in toluene were estimated for each species using the conductor-like screening model (COSMO-RS) were performed using the COSMO-RS module of the ADF program suite. ${ }^{27,28}$ Single point solvation energies are calculated using BP/TZVP level since this was the level of theory for which it was parametrized. Geometries were not reoptimized in the solution phase. These solvation energies $\left(\Delta G_{\text {solv }}\right)$ are then combined with the accurate gas-phase energies $\left(\Delta G_{\text {gas }}\right)$ via a Hess cycle to obtain the solution free energies.

$$
\Delta G_{\text {soln }}=\Delta G_{g a s}+\Delta G_{s o l v}+\Delta G^{1 \mathrm{~atm} \rightarrow 1 \mathrm{M}}
$$

In this equation $\Delta G^{1 \mathrm{~atm} \rightarrow 1 \mathrm{M}}$, is required for converting from the gas-phase standard state for an ideal gas (typically $1 \mathrm{~atm}$ ) to 1 $\mathrm{M}$ in solution

$$
\Delta G^{1 \mathrm{~atm} \rightarrow 1 \mathrm{M}}=\Delta n R T \ln (V)=\Delta n R T \ln \left(\frac{R T}{P}\right)
$$

where $\Delta n$ is the number of moles of gas change from reactants to products. Having made this correction for the change in state, the standard unit of concentration in the solution-phase rate constant expression, eq 1 , becomes $c^{\circ}=1 \mathrm{~mol} \mathrm{~L}^{-1}$, rather than its value for an ideal gas (e.g., $0.0408 \mathrm{~mol} \mathrm{~L}^{-1}$ at room temperature and pressure). 
Table 1. Derived Kinetic Parameters for Gas Phase Reactions of Substituted 3-Phenylpropyl Radicals at 298-353 K ${ }^{a}$

\begin{tabular}{|c|c|c|c|c|c|c|c|c|c|c|c|c|c|c|c|c|}
\hline & \multicolumn{6}{|c|}{ cyclization $^{b}$} & \multicolumn{6}{|c|}{$\beta$-fragmentation } & \multicolumn{4}{|c|}{ addition } \\
\hline & $\Delta H^{\neq c}$ & $\Delta S^{\neq d}$ & $\Delta H_{\mathrm{R}}^{c}$ & $\Delta S_{\mathrm{R}}{ }^{d}$ & $E_{\mathrm{A}}^{c}$ & $\log _{10} A^{e}$ & $\Delta H^{\neq c}$ & $\Delta S^{\ddagger d}$ & $\Delta H_{\mathrm{R}}{ }^{c}$ & $\Delta S_{\mathrm{R}}{ }^{d}$ & $E_{\mathrm{A}}^{c}$ & $\log _{10} A^{e}$ & $\Delta H^{\neq c}$ & $\Delta S^{\neq d}$ & $E_{\mathrm{A}}^{c}$ & $\log _{10} A^{e}$ \\
\hline $1 \mathrm{a}$ & 15.6 & -10.6 & -4.5 & -12.6 & 16.2 & 10.9 & 20.8 & -0.1 & 10.7 & 31.7 & 21.5 & 13.2 & 10.1 & -31.9 & 11.4 & 8.1 \\
\hline $1 b$ & $14.6,13.6$ & $-12.4,-15.4$ & $-4.9,-4.5$ & $-15.8,-16.3$ & $15.3,14.2$ & $10.5,9.9$ & 20.5 & -3.1 & 10.7 & 31.3 & 21.2 & 12.6 & 9.8 & -34.3 & 11.1 & 7.6 \\
\hline $1 \mathrm{c}$ & $13.3,14.9$ & $-11.9,-10.8$ & $-7.1,-7.2$ & $-13.5,-13.3$ & $13.9,15.5$ & $10.7,10.9$ & 20.6 & 0.9 & 10.2 & 32.8 & 21.3 & 13.4 & 10.4 & -31.9 & 11.7 & 8.1 \\
\hline $1 d$ & $13.1,13.7$ & $-11.8,-13.8$ & $-2.6,-1.9$ & $-16.3,-16.8$ & $13.7,14.3$ & $10.7,10.2$ & 21.6 & -3.7 & 12.5 & 34.6 & 22.2 & 12.4 & 9.0 & -38.4 & 10.3 & 6.7 \\
\hline $1 \mathrm{e}$ & $16.1,16.2$ & $-8.0,-10.5$ & $1.5,2.1$ & $-9.9,-10.2$ & $16.7,16.8$ & $11.5,11.0$ & 23.9 & 0.0 & 17.8 & 36.3 & 24.5 & 13.3 & 6.0 & -36.3 & 7.3 & 7.2 \\
\hline If & $22.2,22.4$ & $-12.0,-12.5$ & $9.7,9.9$ & $-11.2,-11.3$ & $22.8,23.0$ & $10.6,10.5$ & 28.3 & -1.5 & 21.8 & 34.6 & 28.9 & 12.9 & 6.6 & -36.1 & 7.8 & 7.2 \\
\hline $1 \mathrm{~g}$ & $18.1,18.0$ & $-8.4,-12.3$ & $5.4,6.1$ & $-10.6,-11.3$ & $18.7,18.6$ & $11.4,10.6$ & 26.0 & 0.8 & 20.3 & 37.4 & 26.6 & 13.4 & 5.7 & -36.6 & 7.0 & 7.1 \\
\hline $2 b$ & $15.1,14.9$ & $-10.9,-11.9$ & $-4.2,-5.2$ & $-13.0,-13.1$ & $15.7,15.5$ & $10.9,10.7$ & 20.3 & -5.4 & 9.8 & 34.0 & 20.9 & 12.1 & 10.5 & -39.4 & 11.7 & 6.5 \\
\hline $2 c$ & $15.7,14.8$ & $-10.4,-10.8$ & $-5.9,-4.3$ & $-13.3,-12.6$ & $16.3,15.4$ & $11.0,10.9$ & 23.4 & -2.5 & 12.3 & 33.7 & 24.0 & 12.7 & 11.0 & -36.2 & 12.3 & 7.2 \\
\hline $2 d$ & $15.0,15.0$ & $-11.7,-12.6$ & $-2.1,-4.7$ & $-16.8,-15.7$ & $15.6,15.6$ & $10.7,10.5$ & 20.0 & -1.6 & 9.7 & 35.5 & 20.6 & 12.9 & 10.2 & -37.1 & 11.5 & 7.0 \\
\hline $2 \mathrm{e}$ & $14.3,14.4$ & $-9.3,-6.6$ & $-6.0,-6.2$ & $-8.5,-9.0$ & $14.9,15.1$ & $11.2,11.8$ & 18.3 & 0.0 & 9.5 & 37.3 & 19.0 & 13.3 & 8.8 & -37.3 & 10.1 & 7.0 \\
\hline $2 f$ & $14.2,14.6$ & $-11.2,-10.6$ & $-4.4,-5.2$ & $-13.4,-13.7$ & $14.8,15.3$ & $10.8,10.9$ & 18.1 & -4.5 & 5.8 & 32.9 & 18.7 & 12.3 & 12.3 & -37.4 & 13.6 & 7.0 \\
\hline $2 \mathrm{~g}$ & $15.3,15.8$ & $-11.6,-8.5$ & $-4.4,-5.2$ & $-12.8,-12.8$ & $15.9,16.4$ & $10.7,11.4$ & 18.1 & -2.5 & 8.9 & 35.4 & 18.8 & 12.7 & 9.2 & -37.9 & 10.5 & 6.8 \\
\hline $3 b$ & $15.4,14.4$ & $-10.1,-10.7$ & $-5.5,-5.2$ & $-12.3,-12.2$ & $16.0,15.1$ & $11.1,10.9$ & 19.2 & 0.1 & 9.9 & 34.3 & 19.9 & 13.3 & 9.3 & -34.2 & 10.6 & 7.6 \\
\hline $3 \mathrm{c}$ & $14.6,15.6$ & $-9.6,-9.8$ & $-4.3,-4.5$ & $-9.2,-11.4$ & $15.2,16.3$ & $11.1,11.1$ & 23.2 & 1.0 & 13.6 & 33.7 & 23.8 & 13.5 & 9.6 & -32.7 & 10.9 & 8.0 \\
\hline $3 d$ & $16.8,17.0$ & $-10.6,-10.6$ & $-2.5,-2.6$ & $-14.4,-14.8$ & $17.4,17.6$ & $10.9,10.9$ & 20.1 & -6.6 & 9.8 & 33.2 & 20.7 & 11.8 & 10.3 & -39.7 & 11.6 & 6.4 \\
\hline $3 e$ & $14.8,14.3$ & $-6.8,-6.9$ & $-5.0,-5.0$ & $-8.8,-8.2$ & $15.4,15.0$ & $11.8,11.7$ & 15.4 & 0.3 & 5.4 & 35.9 & 16.0 & 13.3 & 9.9 & -35.6 & 11.2 & 7.3 \\
\hline $3 f$ & $15.7,14.6$ & $-8.1,-11.5$ & $-6.0,-5.7$ & $-11.9,-11.1$ & $16.3,15.3$ & $11.5,10.7$ & 14.8 & -2.2 & 0.7 & 33.1 & 15.5 & 12.8 & 14.2 & -35.3 & 15.4 & 7.4 \\
\hline $3 g$ & $14.9,14.8$ & $-12.0,-10.8$ & $-6.1,-5.6$ & $-11.3,-9.5$ & $15.6,15.4$ & $10.6,10.9$ & 17.9 & -3.0 & 5.9 & 32.7 & 18.5 & 12.6 & 12.0 & -35.8 & 13.3 & 7.3 \\
\hline $4 h$ & 16.4 & -7.9 & -2.9 & -9.5 & 17.1 & 11.5 & 16.6 & -0.9 & -3.4 & 35.8 & 17.2 & 13.1 & 20.0 & -36.7 & 21.3 & 7.1 \\
\hline $4 \mathrm{i}$ & 16.3 & -10.6 & -1.7 & -10.6 & 16.9 & 10.9 & 18.3 & 3.6 & 17.3 & 34.4 & 18.9 & 14.0 & 1.0 & -30.9 & 2.2 & 8.4 \\
\hline $4 j$ & 21.9 & -9.7 & 1.6 & -9.6 & 22.6 & 11.1 & 18.6 & 0.2 & 6.6 & 36.3 & 19.2 & 13.3 & 12.0 & -36.1 & 13.3 & 7.2 \\
\hline $5 \mathrm{~h}$ & 13.7 & -8.3 & -8.5 & -8.5 & 14.3 & 11.5 & 18.0 & 0.7 & -6.6 & 36.7 & 18.7 & 13.4 & 24.7 & -35.9 & 26.0 & 7.3 \\
\hline $5 \mathrm{i}$ & 11.9 & -12.0 & -11.6 & -13.1 & 12.6 & 10.6 & 4.5 & -0.2 & 0.8 & 31.1 & 5.1 & 13.2 & 3.7 & -31.3 & 5.0 & 8.3 \\
\hline $5 \mathbf{j}$ & 14.0 & -9.6 & -8.4 & -9.3 & 14.6 & 11.2 & 17.4 & -1.8 & 5.7 & 34.8 & 18.0 & 12.9 & 11.7 & -36.6 & 13.0 & 7.1 \\
\hline
\end{tabular}

${ }^{a}$ Using in vacuo G3(MP2)-RAD energies and CT-C $\omega$ hindered rotor corrections for torsional modes. ${ }^{b}$ syn-Cyclization listed first, anti- second. ${ }^{c} \mathrm{kcal}$ $\mathrm{mol}^{-1} \cdot{ }^{d} \mathrm{cal} \mathrm{mol}{ }^{-1} \mathrm{~K}^{-1} \cdot{ }^{e} \log _{10}(A \cdot \mathrm{M} \mathrm{s})$ for addition, $\log _{10}(A \cdot \mathrm{s})$ for cyclization and $\beta$-fragmentation.

\section{RESULTS AND DISCUSSION}

General Features. The potential fates of the variously substituted 3-phenylpropyl free radicals are outlined in Scheme 1, and each of these fates was investigated computationally, including the heterosubstituted species $\mathbf{4 h}-\mathbf{j}$ and $\mathbf{5} \mathbf{h}-\mathbf{j}$. It may be seen from Scheme 1 that cyclization of substituted species may yield diastereomeric free radical species, where the substituent may be either syn- or anti- to the hydrogen on the (formerly) aromatic ring. Under the synthetic schemes of Zard and others, oxidative rearomatization will result in the annihilation of one of the stereogenic centers; however such considerations may become important in systems bearing more than one substituent.

The transition state for cyclization is broadly similar to the transition state for addition, but is a geometrically tighter (or "later" with respect to the 3-phenylpropyl radical) one: the length of the forming $\mathrm{C}-\mathrm{C}$ bond in cyclization is generally shorter than that for addition $/ \beta$-fragmentation, and the angle of approach has significantly greater deviation from the approximately tetrahedral angle of approach calculated for benzyl addition to alkenes (Figure 1). The barrier for cyclization is increased due to the fact that the former system is rotationally constrained away from the lowest energy conformer. The dihedral angle $\angle \mathrm{C}_{1} \mathrm{C}_{2} \mathrm{C}_{3} \mathrm{C}_{\mathrm{Ar}}$ for 3-phenylpropyl radical in its cyclization transition state is $-35.9^{\circ}$, compared to approximately $180^{\circ}$ in the minimum energy structure. Conformational analysis of 3-phenylpropyl radical at the $\mathrm{B} 3 \mathrm{LYP} / 6-31 \mathrm{G}^{*}$ level of theory indicates that rotation of the group bearing the radical center into the conformation required for reaction (i.e., a $-35.9^{\circ}$ dihedral angle) carries a steric penalty of approximately $2.9 \mathrm{kcal} / \mathrm{mol}$, with a barrier to the rotation (a change in dihedral from $180^{\circ}$ to $0^{\circ}$ ) of $3.6 \mathrm{kcal} / \mathrm{mol}$. Analogous barriers calculated for 1 -fluoro - and 1,3diphenylpropyl radicals were 3.0 and $3.5 \mathrm{kcal} / \mathrm{mol}$, respectively, at the same level of theory. We note that the barriers were calculated with relaxed redundant coordinate scans that did not include any stabilizing effects due to the formation of the $\mathrm{C}-\mathrm{C}$ bond in the transition state. It seems clear that conformational effects, while significant, are not dominant contributors to the activation barrier for cyclization. However, the conformationally constrained nature of the cyclization reaction may be anticipated to exert entropic effects, which will be manifested in the Arrhenius pre-exponential (see below).

Natural population analysis ${ }^{29}$ of the 3-phenylpropyl radical and the transition states for fragmentation and cyclization at the B3LYP/6-31G* level of theory (Figure 1), indicate that charge transfer contributors play a relatively minor role in the fragmentation transition state-the benzyl and ethylene fragments are essentially neutral overall, although there is a degree of localized charge separation, where the benzylic carbon appears to be relatively electron poor, and the "tail" of the ethylene, such as it is, is slightly electron rich. Nonetheless, there is not the same degree of charge transfer character as there is in other addition reactions (for example, the addition of hydroxyl radical to arenes). ${ }^{30}$ 
Table 2. Derived Kinetic Parameters for Solution Phase Reactions of Substituted 3-Phenylpropyl Radicals at 298-353 K ${ }^{a}$

\begin{tabular}{|c|c|c|c|c|c|c|c|c|c|c|c|c|c|c|c|c|}
\hline & & & cycl & & & & & & & nta & & & & addi & & \\
\hline & $\Delta H^{\ddagger c}$ & $\Delta S^{\neq d}$ & $\Delta H_{\mathrm{R}}{ }^{c}$ & $\Delta S_{R}^{d}$ & $E_{\mathrm{A}}{ }^{c}$ & $\log _{10} A^{e}$ & $\Delta H^{\neq c}$ & $\Delta S^{\ddagger d}$ & $\Delta H_{\mathrm{R}}{ }^{c}$ & $\Delta S_{\mathrm{R}}{ }^{d}$ & $E_{\mathrm{A}}{ }^{c}$ & $\log _{10} A^{e}$ & $\Delta H^{\neq c}$ & $\Delta S^{\ddagger d}$ & $E_{\mathrm{A}}{ }^{c}$ & $\log _{10} A^{e}$ \\
\hline 1a & 16.0 & -10.4 & -4.5 & -12.2 & 16.6 & 11.0 & 20.4 & -0.3 & 8.9 & 18.2 & 21.0 & 13.2 & 11.5 & -18.5 & 12.2 & 9.2 \\
\hline $1 b$ & $15.2,14.2$ & $12.3,-15.2$ & $-4.8,-4.3$ & $-15.6,-15.9$ & $15.8,14.8$ & $10.6,9.9$ & 20.1 & -3.3 & 8.8 & 17.6 & 20.7 & 12.5 & 11.3 & -20.8 & 11.9 & 8.7 \\
\hline $1 \mathrm{c}$ & $13.9,14.8$ & $-11.7,-10.9$ & $-7.3,-8.1$ & $-13.5,-13.6$ & $14.5,15.4$ & $10.7,10.9$ & 20.3 & 0.7 & 8.5 & 19.3 & 20.9 & 13.4 & 11.8 & -18.6 & 12.4 & 9.2 \\
\hline $1 d$ & $13.8,14.1$ & $-11.7,-13.7$ & $-2.4,-2.3$ & $-16.0,-16.8$ & $14.4,14.7$ & $10.7,10.3$ & 20.8 & -4.0 & 10.4 & 20.7 & 21.4 & 12.4 & 10.4 & -24.7 & 11.1 & 7.9 \\
\hline le & $16.4,15.8$ & $8.0,-10.7$ & $.6,1.4$ & $-9.7,-10.2$ & $17.0,16.4$ & $11.5,10.9$ & 23.2 & -0.2 & 16.0 & 22.9 & 23.8 & 13.2 & 7.2 & -23.2 & 7.8 & 8.2 \\
\hline 1f & $23.0,23.1$ & $-11.7,-12.3$ & $9.9,10.1$ & $-10.9,-11.0$ & $23.6,23.8$ & $10.7,10.6$ & 27.9 & -1.7 & 19.9 & 21.0 & 28.5 & 12.9 & 8.0 & -22.6 & 8.6 & 8.3 \\
\hline $1 \mathrm{~g}$ & $19.1,18.8$ & $-8.2,-12.1$ & $5.8,6.6$ & $-10.3,-10.8$ & $19.8,19.5$ & $11.5,10.6$ & 25.8 & 0.7 & 18.4 & 23.8 & 26.4 & 13.4 & 7.4 & -23.1 & 8.1 & 8.2 \\
\hline $2 b$ & $15.4,15.3$ & $-10.8,-11.8$ & $-4.3,-5.4$ & $-12.8,-12.9$ & $16.0,15.9$ & $10.9,10.7$ & 20.0 & -5.5 & 7.7 & 20.3 & 20.6 & 12.0 & 12.3 & -25.8 & 12.9 & 7.6 \\
\hline $2 c$ & $15.9,14.6$ & $-10.4,-10.9$ & $-6.1,-4.6$ & $-13.1,-12.5$ & $16.5,15.2$ & $11.0,10.9$ & 23.1 & -2.4 & 10.7 & 20.5 & 23.7 & 12.7 & 12.3 & -22.8 & 13.0 & 8.3 \\
\hline $2 d$ & $15.3,15.0$ & $-11.7,-12.6$ & & $-17.0,-15.6$ & & & 21.6 & -1.6 & 7.1 & 21.6 & 20.6 & & 12.9 & & .5 & 8.2 \\
\hline $2 e$ & $14.4,14.2$ & $-9.4,-6.6$ & $-6.4,-6.7$ & $-8.5,-9.1$ & $15.0,14.9$ & $11.2,11.8$ & 18.2 & 0.2 & 7.5 & 23.9 & 18.8 & 13.3 & 10.7 & -23.7 & 11.3 & 8.1 \\
\hline $2 \mathrm{f}$ & $14.4,15.0$ & $-11.3,-10.5$ & $-4.5,-5.5$ & $-13.2,-13.5$ & $15.0,15.6$ & $10.8,11.0$ & 18.1 & -4.5 & 3.7 & 19.2 & 18.7 & 12.3 & 14.4 & -23.7 & 15.0 & 8.1 \\
\hline $2 g$ & $15.4,15.9$ & $-11.8,-8.6$ & $-4.5,-5.3$ & $-12.7,-12.7$ & $16.0,16.6$ & $10.7,11.4$ & 17.8 & -2.8 & 6.5 & 21.6 & 18.4 & 12.6 & 11.3 & -24.4 & 11.9 & 7.9 \\
\hline $3 b$ & $15.8,14.8$ & $-9.9,-10.5$ & $-5.6,-5.2$ & $-12.0,-11.8$ & $16.4,15.5$ & $11.1,11.0$ & 19.0 & 0.0 & 8.0 & 20.8 & 19.6 & 13.2 & 10.9 & -20.8 & 11.6 & 8.7 \\
\hline $3 c$ & $14.8,16.0$ & $-9.7,-9.8$ & $-4.7,-4.9$ & $-9.3,-11.4$ & $15.4,16.6$ & $11.1,11.1$ & 23.2 & 1.0 & 12.3 & 20.5 & 23.8 & 13.5 & 10.9 & -19.5 & 11.5 & 9.0 \\
\hline $3 d$ & $16.5,16.8$ & $-10.9,-10.7$ & $-3.3,-3.4$ & $-14.6,-14.9$ & $17.2,17.4$ & $10.9,10.9$ & 19.4 & -6.9 & 7.0 & 19.2 & 20.1 & 11.8 & 12.4 & -26.0 & 13.1 & 7.6 \\
\hline $3 e$ & $15.0,14.7$ & $-6.8,-6.9$ & $-5.5,-5.4$ & $-8.8,-8.1$ & $15.6,15.3$ & $11.8,11.7$ & 15.2 & 0.1 & 4.0 & 22.6 & 15.9 & 13.3 & 11.2 & -22.5 & 11.9 & 8.3 \\
\hline $3 f$ & $16.0,15.0$ & $-8.0,-11.3$ & $-6.0,-5.6$ & $-11.6,-10.6$ & $16.6,15.7$ & $11.5,10.8$ & 14.8 & -2.3 & -1.2 & 19.5 & 15.4 & 12.7 & 16.0 & -21.9 & 16.6 & 8.5 \\
\hline $3 g$ & $15.2,15.0$ & $-11.9,-10.7$ & $-6.3,-5.7$ & $-11.1,-9.2$ & $15.9,15.7$ & $10.6,10.9$ & 17.7 & -3.2 & 4.0 & 19.2 & 18.3 & 12.5 & 13.7 & -22.4 & 14.3 & 8.4 \\
\hline $4 h$ & 11.1 & -7.8 & -3.2 & -9.4 & 17.7 & 11.5 & 16.3 & -1.1 & -6.1 & 21.6 & 16.9 & 13.0 & 22.3 & -22.7 & 22.9 & 8.3 \\
\hline $4 i$ & 16.9 & -10.5 & -1.9 & -10.5 & 17.5 & 11.0 & 17.6 & 3.2 & 16.0 & 21.0 & 18.2 & 14.0 & 1.6 & -17.8 & 2.3 & 9.4 \\
\hline $4 j$ & 22.3 & -9.5 & 1.5 & -9.5 & 22.9 & 11.2 & 18.6 & 0.1 & 4.2 & 22.1 & 19.2 & 13.3 & 14.4 & -22.0 & 15.0 & 8.5 \\
\hline $5 \mathrm{~h}$ & 14.2 & -8.2 & -8.8 & -8.2 & 14.8 & 11.5 & 17.7 & 0.2 & -9.7 & 22.2 & 18.3 & 13.3 & 27.4 & -22.0 & 28.0 & 8.4 \\
\hline $5 \mathrm{i}$ & 12.3 & -12.0 & -11.9 & -12.0 & 12.9 & 10.6 & 4.1 & -0.4 & -0.8 & 17.7 & 4.7 & 13.2 & 4.8 & -18.1 & 5.5 & 9.3 \\
\hline $5 j$ & 14.4 & -9.5 & -8.9 & -9.5 & 15.0 & 11.2 & 17.7 & -1.7 & 3.9 & 20.9 & 18.3 & 12.9 & 13.8 & -22.7 & 14.5 & 8.3 \\
\hline
\end{tabular}

${ }^{a}$ Using in vacuo G3(MP2)-RAD energies and hindered rotor corrections for torsional modes. Solvation energies calculated by COSMO-RS using toluene as solvent. ${ }^{b}$ syn-Cyclization listed first, anti- second. ${ }^{c} \mathrm{kcal} \mathrm{mol}^{-1} \cdot{ }^{d} \mathrm{cal} \mathrm{mol}^{-1} \mathrm{~K}^{-1} \cdot{ }^{e} \log _{10}(A \cdot \mathrm{M} \mathrm{s})$ for addition, $\log _{10}(A \cdot \mathrm{s})$ for $\mathrm{cyclization}$ and $\beta$-fragmentation.

Table 3. Comparison of Computed and Experimental Energy Barriers for Addition of Benzyl Radical to Alkenes

\begin{tabular}{|c|c|c|c|c|}
\hline alkene/computational analogue & & $k_{\text {add }}\left(\mathrm{M}^{-1} \mathrm{~s}^{-1}, 298 \mathrm{~K}\right)$ & $E_{\mathrm{A}, \mathrm{add}}(\mathrm{kcal} / \mathrm{mol})$ & $\log _{10}\left(A_{\text {add }} \cdot \mathrm{Ms}\right)$ \\
\hline \multirow[t]{3}{*}{ but-1-ene/propene } & $\operatorname{expt}^{a}$ & $3.3 \times 10^{1}$ & 9.4 & 8.6 \\
\hline & $\operatorname{calcd}(\mathrm{g})^{b}$ & $2.9 \times 10^{-1}$ & 11.1 & 7.6 \\
\hline & $\operatorname{calcd}(s)^{c}$ & $9.9 \times 10^{-1}$ & 11.9 & 8.7 \\
\hline \multirow[t]{3}{*}{ ethyl vinyl ether/methyl vinyl ether } & $\operatorname{expt}^{a}$ & $1.4 \times 10^{1}$ & 9.9 & 10.2 \\
\hline & $\operatorname{calcd}(\mathrm{g})^{b}$ & $1.6 \times 10^{-1}$ & 10.3 & 6.7 \\
\hline & $\operatorname{calcd}(s)^{c}$ & $5.7 \times 10^{-1}$ & 11.1 & 7.9 \\
\hline \multirow[t]{3}{*}{ acrylonitrile/acrylonitrile } & $\operatorname{expt}^{a}$ & $2.2 \times 10^{3}$ & 7.0 & 8.9 \\
\hline & $\operatorname{calcd}(\mathrm{g})^{b}$ & $6.7 \times 10^{1}$ & 7.3 & 7.2 \\
\hline & $\operatorname{calcd}(s)^{c}$ & $2.8 \times 10^{2}$ & 7.8 & 8.2 \\
\hline \multirow[t]{3}{*}{ styrene/styrene } & $\operatorname{expt}^{a}$ & $1.1 \times 10^{3}$ & 7.4 & 8.6 \\
\hline & $\operatorname{calcd}(\mathrm{g})^{b}$ & $1.0 \times 10^{2}$ & 7.0 & 7.1 \\
\hline & $\operatorname{calcd}(s)^{c}$ & $2.0 \times 10^{2}$ & 8.1 & 8.2 \\
\hline
\end{tabular}

${ }^{a}$ From Fischer et al. ${ }^{1,2 b}$ Gas phase data calculated at G3(MP2)-RAD, with CT-C $\omega$ anharmonic correction for torsional modes in the evaluation of partition functions. ${ }^{c}$ As for footnote, ${ }^{b}$ but with additional solvation corrections with COSMO-RS.

The spin density in the transition state is mainly distributed on $\mathrm{C} 1$ and $\mathrm{C} 3$ of the forming 3-phenylpropyl system, as expected.

Determining charge transfer character in the cyclization transition state is somewhat more difficult as the reaction is unimolecular. However, upon separation of the system into propyl radical and benzene fragments, there is little evidence of significant charge transfer in the transition state. This is consistent with the Fischer and Radom characterization of alkyl radicals as being only very weakly nucleophilic. ${ }^{2}$ Fischer and Radom argued that the benzyl radical is a more nucleophilic species, but its nucleophilic effects are ameliorated or canceled by smaller charge-transfer contributions in the transition state.

The kinetic and thermodynamic parameters for cyclization and $\beta$-fragmentation of compounds $\mathbf{1 - 5}$ in the gas phase are 


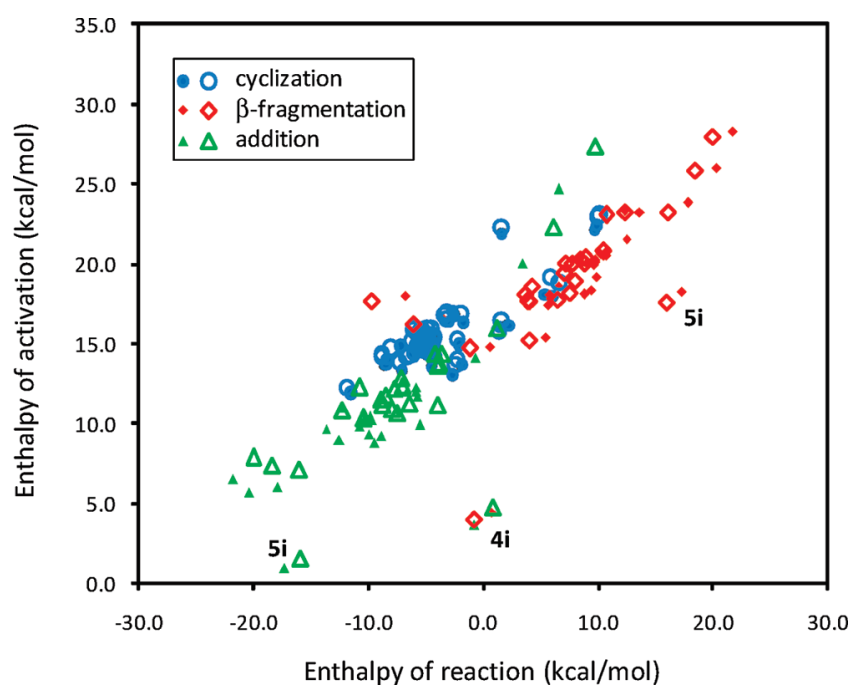

Figure 2. Evans-Polanyi-Semenov correlation for addition, $\beta$-fragmentation and cyclization reactions of substituted 3-phenylpropyl radicals. Closed symbols correspond to gas phase (G3(MP2)-RAD, CT-C $\omega$ corrections), and open symbols to solution phase (G3(MP2)$\mathrm{RAD}, \mathrm{CT}-\mathrm{C} \omega$, COSMO-RS corrections) calculations. Excluding heterosubstitutions in the chain, the entire data set may be fitted to $\Delta H^{+}=$ $16.0 \mathrm{kcal} / \mathrm{mol}+0.470 \Delta H_{\mathrm{r}}\left(R^{2}=0.899\right)$; exclusion of only $4 \mathbf{i}$ and $5 \mathbf{i}$ gives to $\Delta H^{\ddagger}=16.3 \mathrm{kcal} / \mathrm{mol}+0.473 \Delta H_{\mathrm{r}}\left(R^{2}=0.851\right)$.

summarized in Table 1. These parameters were calculated with the inclusion of hindered rotor corrections for torsional modes on the kinetics of reaction. As expected, the effect of including CT-C $\omega$ corrections on enthalpic parameters $\left(\Delta H_{\mathrm{R}}, \Delta H^{\ddagger}\right.$, and $\left.E_{\mathrm{A}}\right)$ is small; $\leq 0.1 \mathrm{kcal} / \mathrm{mol}$ difference. The effects on entropic parameters and the pre-exponential $A$ are more significant (these can be seen in the Supporting Information). Table 2 summarizes the kinetic and thermodynamic parameters obtained when free energies of solvation in an organic solvent (in this case toluene) are included.

Evaluation of rate coefficients calculated at the G3(MP2)$\mathrm{RAD}$ level of theory, including hindered rotor and solvent corrections, against experimental data is largely limited to comparison with rate coefficients and derived activation barriers estimated by LFP studies on the kinetics of benzyl radical addition. ${ }^{1}$ The comparable data are summarized in Table 3.

By and large, G3MP2-RAD calculations provide a reasonable degree of agreement with respect to activation energies, with discrepancies of approximately $1-2 \mathrm{kcal} / \mathrm{mol}$. Inclusion of solvation free energies from COSMO-RS provides good agreement between experimental and calculated Arrhenius pre-exponentials - one clear outlier is the methyl/ethyl vinyl ether data, where the difference in Arrhenius pre-exponentials is large (2 orders of magnitude). In this case, the experimental value is much higher than for the other reactions of this type and may require re-examination. In addition to the data in Table 3 , it is noteworthy that the fragmentation rate coefficient for 1a in toluene solution is estimated as $1 \times 10^{-2} \mathrm{~s}^{-1}$ at $298 \mathrm{~K}$, compared with the literature value of Gasanov et al. of $4 \times 10^{4} \mathrm{~s}^{-1}$ at $295 \mathrm{~K}^{3}$ This large discrepancy greatly exceeds the estimated uncertainty in the theoretical procedures, which have recently been shown to reproduce related beta-scission reactions to within chemical accuracy, ${ }^{31}$ and it is possible that additional reaction channels may be contributing to an overestimation of the fragmentation rate in this experimental system.
Evans-Polanyi-Semenov type plots of addition, $\beta$-fragmentation and cyclization reactions in this study are shown in Figure 2.

The plots show a reasonable degree of correlation for simple phenylpropyl systems; the outlier data arising from heterosubstitution, particularly thia-substitution in $4 \mathbf{i}$ and $\mathbf{5 i}$. The correlation is not markedly changed in its nature between gas and solution phases. The Semenov model ${ }^{32}$ uses an empirically derived proportionality factor of 0.25 between the enthalpies of activation and reaction, that is

$$
\Delta H^{\dagger}=0.25 \Delta H_{\mathrm{r}}+c
$$

where $c$ is a constant. It may be noted from Figure 2, that the proportionality constants are somewhat higher: on the order of 0.5 for all three reactions. Fischer and Radom argued in their review $^{2}$ that for radical addition reactions, significant deviation from a value of 0.25 indicated that nucleophilic (charge-transfer) effects may be important in such systems. It may also be noted that deviations from the Semenov model may well arise from the fact that this model is predicated on the following conditions:

- The Arrhenius pre-exponentials show little variation (which these reactions generally obey, see Tables 1-3).

- The reactions are significantly exothermic (which many are not). Indeed, Semenov postulated that the proportionality factor would increase in the case of endothermic reactions. ${ }^{21}$

From the earliest of the kinetic studies of radical addition reactions, these reactions have been characterized in terms of "the complex interplay of polar, steric, and bond strength terms". 33

Stabilization/Bond Strength Effects. If we assume that bond strength terms are a reflection of the stability of the reactant and product species, then one would expect to observe correlations between activation energies and the stabilization energies calculated for various functional groups attached to the benzyl radical and the substituted 3-phenylpropyl radicals (which for simplicity and ease of calculation we modeled as variously substituted $n$ butyl radicals). The free radical stabilization energies (RSE) may be estimated for these radicals by consideration of the isodesmic reactions in Scheme 3:

The justification for substituting a 3-methyl group for a 3-phenyl group is supported by the fact that in both cases, the contribution to the radical stabilization energy for 3-phenylbutyl and 3-methylbutyl is approximately the same. Indeed, where the 3 -phenylpropyl system was calculated in addition to the $n$-butyl analogue, variation in RSE values were typically below $1 \mathrm{kcal} /$ mol. The RSE values for the radicals involved were estimated at the G3(MP2)-RAD level of theory (Table 4).

Scheme 3 also includes heterosubstituted systems considered in this study: in the case of the $n$-butyl radicals, the free radical species are all carbon-centered radicals, but in the case of benzylic systems, the bulk of the radical character lies on a heteroatom. With respect to systems such as phenoxyl, phenylthiyl and anilinyl radicals it is unlikely the RSE calculated by an analogous reaction (which is not entirely isodesmic, since $\mathrm{C}-\mathrm{H}$ and $\mathrm{X}-\mathrm{H}$ bond strengths where $\mathrm{X}=\mathrm{N}, \mathrm{O}, \mathrm{S}$ are significantly different) is an accurate indication of the radical stabilization.

Where $\mathrm{C}-\mathrm{C}$ bond formation occurs, all three reactions (addition, $\beta$-fragmentation, and cyclization) exhibit a relatively weak correlation between the enthalpy of activation, and the estimated stabilization energies for the aliphatic $n$-butyl radical species used as a computational analogue of the 3-phenylpropyl 
Scheme 3. Estimation of Stabilization Energies for Substituted Free Radicals and Alkenes

benzyl radicals<smiles>[X]C(C)c1ccccc1</smiles>

3-phenylpropyl radical $\left(\mathrm{R}=\mathrm{C}_{6} \mathrm{H}_{5}\right)$ andanalogues $\left(\mathrm{R}=\mathrm{CH}_{3}\right)$

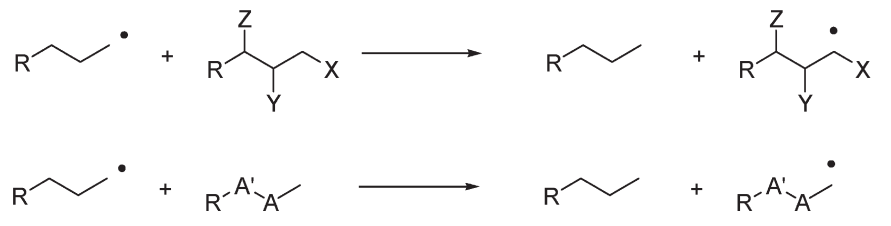

Table 4. Computed Radical Stabilization Energies (RSE) and Vertical (Nonadiabatic) Ionization Potentials (IP $_{\mathbf{v}}$ ) and Electron Affinitites $\left(\mathrm{EA}_{\mathrm{v}}\right)$ for Radicals and Alkenes in this Study ${ }^{a}$

\begin{tabular}{|c|c|c|c|c|c|c|c|c|}
\hline & \multicolumn{3}{|c|}{ benzyl radical } & \multicolumn{2}{|c|}{ alkene } & \multicolumn{3}{|c|}{ 3-phenylpropyl radical } \\
\hline & $\operatorname{RSE}^{b}(\mathrm{kcal} / \mathrm{mol})$ & $\mathrm{IP}_{\mathrm{v}}{ }^{d}(\mathrm{eV})$ & $\mathrm{EA}_{\mathrm{v}}{ }^{d}(\mathrm{eV})$ & $\mathrm{IP}_{\mathrm{v}}{ }^{d}(\mathrm{eV})$ & $\mathrm{EA}_{\mathrm{v}}{ }^{d}(\mathrm{eV})$ & $\operatorname{RSE}^{c}(\mathrm{kcal} / \mathrm{mol})$ & $\mathrm{IP}_{\mathrm{v}}{ }^{d}(\mathrm{eV})$ & $\mathrm{EA}_{\mathrm{v}}{ }^{d}(\mathrm{eV})$ \\
\hline 1a & $0.0^{e}$ & $7.24(7.25)$ & $0.92(0.91)$ & $10.83(10.51)$ & $-1.49(-1.8)$ & $0.0^{e}$ & 8.34 & -0.12 \\
\hline $1 b$ & $0.0^{e}$ & 7.24 & 0.92 & $10.14(9.73)$ & -0.91 & $-2.3(-2.4)$ & 7.59 & -0.46 \\
\hline $1 \mathrm{c}$ & $0.0^{e}$ & 7.24 & 0.92 & $10.76(10.36)$ & -1.03 & $-1.8(-1.8)$ & 8.34 & -0.42 \\
\hline $1 d$ & $0.0^{e}$ & 7.24 & 0.92 & $9.16(8.95)$ & -0.83 & $-6.0(-5.7)$ & 6.96 & -0.54 \\
\hline 1e & $0.0^{e}$ & 7.24 & 0.92 & $11.21(10.91)$ & -0.65 & $-7.7(-7.7)$ & 9.07 & 1.33 \\
\hline If & $0.0^{e}$ & 7.24 & 0.92 & $9.34(9.07)$ & -1.01 & $-16.4(-16.4)$ & 7.48 & 0.30 \\
\hline $1 \mathrm{~g}$ & $0.0^{e}$ & 7.24 & 0.92 & $8.76(8.46)$ & -0.82 & -11.2 & 6.81 & 0.87 \\
\hline $2 b$ & $0.0^{e}$ & 7.24 & 0.92 & 10.14 & -0.91 & $0.0(0.5)$ & 8.30 & -0.04 \\
\hline $2 c$ & $0.0^{e}$ & 7.24 & 0.92 & 10.76 & -1.03 & $1.6(1.7)$ & 8.90 & 0.23 \\
\hline $2 d$ & $0.0^{e}$ & 7.24 & 0.92 & 9.16 & -0.83 & $0.4(0.6)$ & 8.53 & 0.16 \\
\hline $2 e$ & $0.0^{e}$ & 7.24 & 0.92 & 11.21 & -0.65 & $1.5(1.7)$ & 9.10 & 0.60 \\
\hline $2 \mathrm{f}$ & $0.0^{e}$ & 7.24 & 0.92 & 9.34 & -1.01 & $0.2(0.9)$ & 8.22 & 0.18 \\
\hline $2 g$ & $0.0^{e}$ & 7.24 & 0.92 & 8.76 & -0.82 & -0.2 & 8.01 & 0.23 \\
\hline $3 b$ & -2.1 & 6.90 & 0.81 & 10.83 & -1.49 & $-0.7(-0.5)$ & 8.32 & -0.21 \\
\hline $3 c$ & -2.3 & 7.18 & 0.82 & 10.83 & -1.49 & $0.1(0.2)$ & 8.63 & -0.08 \\
\hline $3 d$ & -7.0 & 6.30 & 0.47 & 10.83 & -1.49 & $-0.2(-0.1)$ & 8.28 & -0.22 \\
\hline $3 e$ & -6.7 & 7.95 & 2.05 & 10.83 & -1.49 & $0.5(0.5)$ & 8.88 & 0.37 \\
\hline $3 f$ & -11.3 & 6.90 & 1.18 & 10.83 & -1.49 & $-0.4(-0.2)$ & 8.23 & 0.04 \\
\hline $3 g$ & -6.1 & 6.49 & 1.50 & 10.83 & -1.49 & -0.7 & 8.25 & -0.01 \\
\hline $4 h$ & $0.0^{e}$ & 7.24 & 0.92 & $10.99(10.88)$ & -0.94 & $-4.8(-3.9)$ & 7.55 & -0.53 \\
\hline $4 i$ & $0.0^{e}$ & 7.24 & 0.92 & $9.41(9.38)$ & $0.28(0.47)$ & $-7.1(-7.6)$ & 7.09 & -0.06 \\
\hline $4 j$ & $0.0^{e}$ & 7.24 & 0.92 & $10.81(9.97)$ & -0.96 & $-8.2(-7.7)$ & 6.55 & -0.68 \\
\hline $5 \mathrm{~h}$ & & $8.98(8.56)$ & $1.98(2.25)$ & 10.83 & -1.49 & $0.9(1.2)$ & 8.64 & -0.22 \\
\hline $5 \mathrm{i}$ & & $8.55(8.6)$ & $2.43(2.46)$ & 10.83 & -1.49 & $-0.2(-1.5)$ & 8.56 & 0.44 \\
\hline $5 j$ & & $8.07(8.3)$ & $1.65(1.70)$ & 10.83 & -1.49 & $0.1(1.0)$ & 8.55 & -0.07 \\
\hline
\end{tabular}

${ }^{a}$ Values in parentheses correspond to experimentally measured (adiabatic) IP and EA, and were obtained from the NIST chemistry WebBook. ${ }^{b}$ Gas phase data calculated at G3(MP2)-RAD for isodesmic reactions of benzyl radicals in Scheme 3 (Equation I), for heteroatom substitutions, see text. ${ }^{c}$ Gas phase data calculated at G3(MP2)-RAD for isodesmic reactions of substituted $n$-butyl radicals (Scheme 3, eqs II and III); where available, the values for 3-phenylpropyl radicals are included parenthetically. ${ }^{d}$ Gas phase data calculated at G3(MP2)-RAD using the B3LYP/6-31G* optimized geometries for the neutral species (vertical IP and EA). ${ }^{e}$ Defined.

species (Figure 3a). Similar correlations for addition and fragmentation reactions may also be observed with the stabilization energies of the benzyl radical fragments (Figure $3 b$ ).

As would be expected, stabilization of the 3-phenylpropyl species leads to higher activation energies for both fragmentation and cyclization, and smaller reaction barriers for addition. It may be noted from Tables 1 and 2 that certain forms of the cyclized 3-phenylpropyl systems are higher in energy than their diastereomeric alternatives. Diastereomeric forms whereby the functional group $-\mathrm{X}$ (Scheme 2) adopts a pseudoaxial 


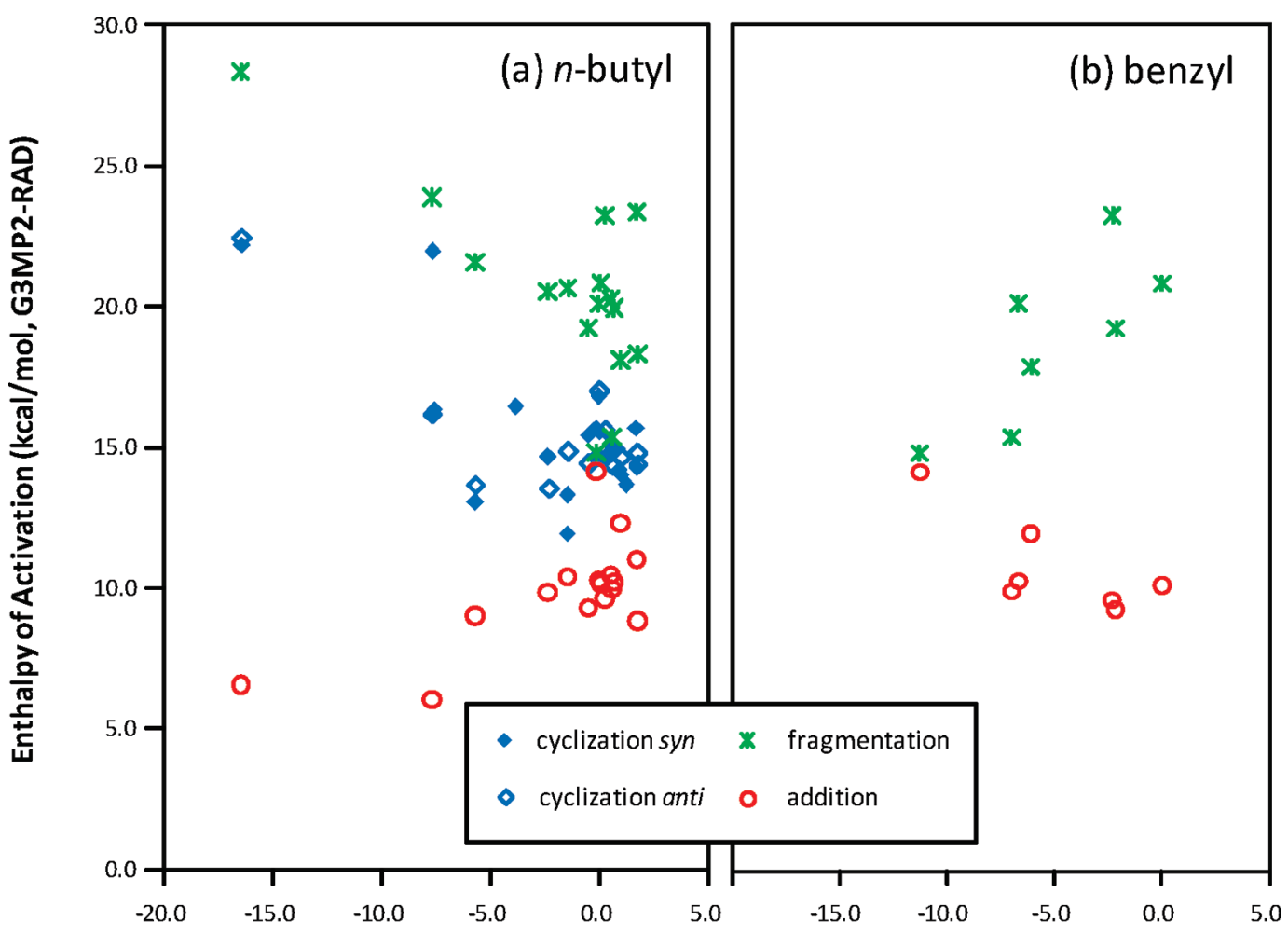

Radical Stabilization Energy (kcal/mol, G3MP2-RAD)

Figure 3. Correlation between the barriers (in solution) for addition, $\beta$-fragmentation and cyclization reactions of substituted 3-phenylpropyl radicals and estimated radical stabilization energies (RSE, see Scheme 3) for their (a) $n$-butyl models and (b) benzyl fragments at G3(MP2)-RAD in vacuo. These correlations do not include heterosubstitions in the chain (see text). Lines of best fit for part a are as follows: fragmentation, $\Delta H^{\ddagger}=19.7 \mathrm{kcal} / \mathrm{mol}-$ $0.495 R S E\left(R^{2}=0.50\right)$; cyclization, $\Delta H^{+}=14.8 \mathrm{kcal} / \mathrm{mol}-0.327 \mathrm{RSE}\left(R^{2}=0.55\right)$, addition: $\Delta H^{\dagger}=10.4 \mathrm{kcal} / \mathrm{mol}+0.277 \mathrm{RSE}\left(R^{2}=0.46\right)$. Lines of best fit for part $\mathrm{b}$ are as follows: fragmentation, $\Delta H^{\dagger}=21.9 \mathrm{kcal} / \mathrm{mol}+0.615 \mathrm{RSE}\left(R^{2}=0.61\right)$; addition, $\Delta H^{\ddagger}=9.0 \mathrm{kcal} / \mathrm{mol}-0.348 \mathrm{RSE}\left(R^{2}=0.60\right)$.

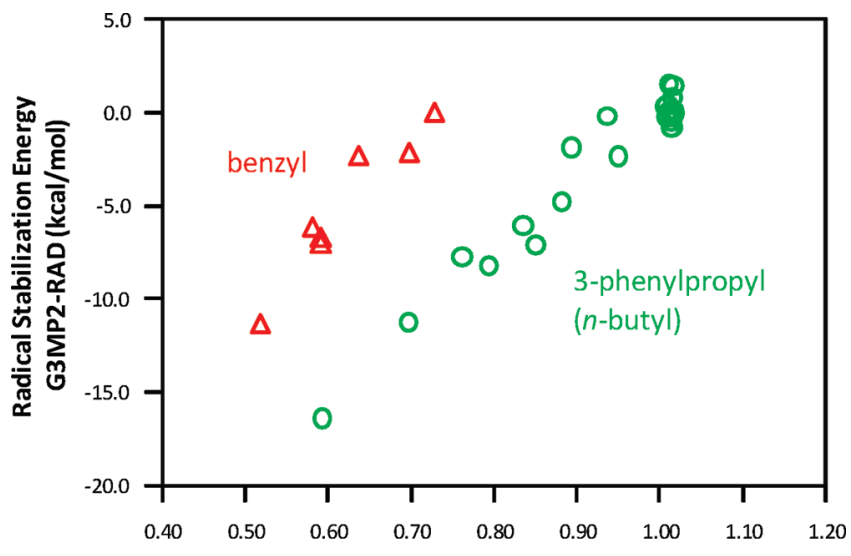

NPA Spin density on carbon (e, B3LYP/631G*)

Figure 4. Correlation of calculated radical stabilization energies, G3MP2-RAD for substituted benzyl and $n$-butyl (as a model for 3-phenylpropyl systems) radicals with NPA spin density (B3LYP/6$\left.31 \mathrm{G}^{*}\right)$ on the radical center. For benzyl radical, RSE $=50.9 \rho-36.6$ $\mathrm{kcal} / \mathrm{mol}\left(R^{2}=0.917\right)$; for butyl radicals, $\mathrm{RSE}=37.2 \rho-37.2 \mathrm{kcal} / \mathrm{mol}$ $\left(R^{2}=0.952\right)$, where $\rho$ is the calculated spin density on carbon.

conformation tend to be higher energy due to transannular steric interactions. In these particular cases the diastereomeric forms are 1- and 3-substituted anti- and 2-substituted synforms. In general terms (although not universally), the transition state leading to the higher energy diastereomer is also higher in energy.

The correlation for addition/fragmentation reactions is somewhat weaker, with a greater degree of scatter in the data. It is likely that this is a reflection of the importance of less quantifiable steric effects. Certainly, it has long been held that the preference of free radicals to prefer "tail" addition (addition to the less substituted end) over "head" addition is to a large extent steric in origin (though these steric preferences are usually reinforced by electronic factors). Such an argument is illustrated by the transition state geometries for fragmentation - it is clear that the fragmentations of 2-substituted systems have earlier (or more reactant-like) transition states than their 1-substituted analogues, based on the transition state bond length of the rupturing $\mathrm{C}-\mathrm{C}$ bond. Presumably the earlier transition state arises from relief of steric strain in the system, where the substituent is more proximal to the (relatively) sterically demanding phenyl group.

The effect of stabilization of the benzyl radical (exhibited in the 3 -substituted systems $3 \mathbf{b}-\mathbf{g}$ ), modifies reactivity in an expected manner: stabilization of the benzyl radical tends to make it less reactive toward addition, but more readily formed by fragmentation.

The radical stabilization scales used from isodesmic analysis are assumed to be a function of the delocalization of spin in the free radical species. Indeed, there is a strong correlation between the stabilization of the free radical (substituted 3-phenylpropyl and benzyl), and the spin density at the carbon atom 
(determined by NPA at the B3LYP/6-31G* level of theory, see Figure 4).

If one includes data for $\mathrm{C}-\mathrm{X}$ bond formation (where $\mathrm{X}=\mathrm{N}$, $\mathrm{O}, \mathrm{S})$ to correlations for addition and fragmentation reactions, one finds that the degree of correlation is significantly poorer (the presence of heteroatoms on cyclization reactions has somewhat less effect, and heterosubstitution data are included for cyclizations in Figure 3a). The effect is particularly pronounced for the group VI elements, less so for nitrogen. It seems likely that in these cases, a simple model based upon radical stabilization may not be sufficient. An alternative stabilization scale, based on the experimental $\mathrm{C}_{6} \mathrm{H}_{5} \mathrm{Y}-\mathrm{H}$ bond dissociation energies $(\mathrm{Y}=$ $-\mathrm{CH}_{2}-,-\mathrm{NH}-,-\mathrm{O}-$, and $-\mathrm{S}-$ ) does not show strong correlation with the enthalpies of activation for the addition and fragmentation reactions of $\mathbf{1 a}$ and $5 \mathrm{~h}-\mathbf{j}$.

Polar Effects. In order to estimate the importance of polar effects, we utilized the same frontier molecular orbital approach utilized by Fischer et al. ${ }^{1,2}$ in the study of radical addition reactions. In radical additions where the attacking radical is viewed as being nucleophilic (such as benzyl), the primary polar interaction (having $\mathrm{Bz}^{+} /$Alkene- character) should be well described by the $\operatorname{SOMO}\left(\mathrm{Bz}^{\circ}\right)-\mathrm{LUMO}$ (alkene) energy gap. The alternative interaction that would be expected for an electrophilic radical $\left(\mathrm{Bz}^{-} /\right.$alkene $^{\bullet+}$ character $)$ would be described by the $\mathrm{SOMO}\left(\mathrm{Bz}^{\circ}\right)-\mathrm{HOMO}$ (alkene) energy gap. Experimentally, these energies are approximated by the relevant ionization potentials (IP) and electron affinities (EA). ${ }^{1}$ In this study, the MO energies were estimated using the vertical (nonadiabatic, no geometry optimization for cation and anion species) ionization energies and electron affinities for variously substituted alkenes, benzyl radicals and n-butyl radicals (considered, as above, the computational analogues of 3-phenylpropyl systems). Once again, vertical IP and EA were estimated at the G3(MP2)-RAD level of theory, at the optimized geometries of the parent neutral species in each case; and the values obtained are summarized in Table 4 . The comparison between calculated $\mathrm{IP}_{\mathrm{v}}$ and experimental IP, and $\mathrm{EA}_{\mathrm{v}}$ and experimental $\mathrm{EA}$ is reasonable, given that in many cases there are significant structural changes between neutral species and their ionic analogues.

Determining the importance of polar effects in cyclization reactions is somewhat more difficult as it is a unimolecular rearrangement, for which the SOMO and LUMO we wish to consider are on the same species. As a first-order approximation, we consider the addition of a suitably substituted $n$-butyl radical onto toluene $\left(\mathrm{IP}_{\mathrm{v}}=9.15 \mathrm{eV}, \mathrm{EA}_{\mathrm{v}}=-0.71 \mathrm{eV}\right.$ at $\mathrm{G} 3(\mathrm{MP} 2)$ $\mathrm{RAD})$.

Correlations between the enthalpy of activation and frontier molecular orbital energy gaps are rendered more complex because there are some cases (most notably in the cyclization analogue of substituted butyl radical and toluene) where the smaller gap, which would be expected to describe a dominant polar contributor, is actually the $\mathrm{SOMO}\left(\mathrm{Bz}^{*}\right)-\mathrm{HOMO}$ (alkene/ arene) energy gap. That is, there are radicals in the data set that may be more properly considered as electrophilic.

Despite a limited data set, the addition of benzyl radical to olefins shows a degree of correlation with the SOMO-LUMO gap consistent with a nucleophilic radical; head addition reactions show a poorer degree of correlation, presumably due to the greater influence of steric effects, given that bond formation occurs adjacent to the functional group on the alkene. As above, inclusion of the heteroatomic systems $\mathbf{4}$ and $\mathbf{5}$ leads to poorer correlations. There is no apparent correlation obtained for the enthalpy of activation for the fragmentation reactions.

Taking the data set for cyclization reactions as a whole, there is little apparent correlation between the SOMO energy of the butyl systems and the enthalpy of activation for cyclization. The relative crudity of the butyl/toluene model precludes definitive conclusions from this data, but the indications are that polar effects play a minor role in governing cyclization reactionsthese reactions are predominantly controlled by stabilization and steric effects.

\section{CONCLUSIONS}

On the basis of the observed correlations, the following conclusions may be drawn regarding the nature and relative importance of the $\beta$-fragmentation and cyclization reactions in the chemistry of 3-phenylpropyl radicals and their heterocyclic analogues:

- The addition of benzyl radicals to alkenes in the tail mode exhibit a strong dependence on radical stabilization, and moderate dependence on polar effects, consistent with the experimental observations of Fischer and co-workers. ${ }^{1,2}$ On the other hand, addition in the head mode is dependent on radical stabilization and steric effects, with little evidence of large polar effects. Such an observation is consistent with the fact that benzyl/alkene pairs combining in the head mode may be susceptible to unfavorable polar interactions if the alkene is substituted with electron-withdrawing groups. In any case, it is generally held that addition in the head mode is a thermally unfavorable reaction relative to tail addition, and this is borne out in our study.

- The cyclization reaction exhibits a high degree of EvansPolanyi correlation, and the activation barriers for cyclization are controlled to a large extent by the stabilization of the 3-phenylpropyl radical. Polar effects may be contributors to cyclization reaction barriers, but these are subordinate to radical stabilization effects.

- Steric effects are important in the cyclization reaction-of the diastereomeric radicals that may be formed from these reactions; the higher energy diastereomer generally arises from the higher energy transition state. The energy differences between diastereomers generally arise from transannular reactions of substituents in the pseudoaxial positions.

- Cyclization reactions have lower reaction barriers than fragmentation reactions, although there is an entropic cost to the conformationally restrained transition state for cyclization that leads to a reduction in the Arrhenius preexponential of approximately 2 orders of magnitude. Typically, it appears that in the absence of olefinic material, cyclization is favored over fragmentation, suggesting that cyclization may be of general utility synthetically under persistent radical (aminoxyl) conditions.

- Notable exceptions to the above are those involving heterosubstitutions in the chain, particularly thia- substitutions. Experimentally, the heterosubstituted systems that successfully undergo cyclization are those that are substituted in such a way that fragmentation is prevented or at least unlikely (e.g., amide containing side chains). In addition, in situations where highly stabilized benzylic radicals may be formed such as $3 \mathbf{e}-\mathrm{g}$, fragmentation may compete with cyclization.

- There is little evidence to suggest that cyclization reactions can successfully compete with addition reactions in the tail 
mode with industrial monomers at relevant concentrations. Similarly, fragmentation reactions are also unlikely to compete to any significant extent, and reversibility of reaction is unlikely to contribute significantly to any observed penultimate unit effect in free radical copolymerization.

These studies indicate that there are some limitations to the general applicability to the oxidative radical cyclization approach for the generation of indanes and their heteroanalogues. However, the chemistry of the 3-phenylpropyl radicals, in the absence of alkenes, is most likely to be dominated by radical cyclization. In the presence of alkenes at any experimentally relevant concentration, based on enthalpic considerations, it is likely that radical addition reactions would dominate. In particular, 1-substituted 3-phenylpropyl radicals, which would arise from tail addition in the copolymerization of styrenic monomers with other alkenes, fragmentations are energetically disfavored. If we consider the differences in Arrhenius pre-exponential between the bimolecular addition reaction (estimated experimentally as $\log _{10} A_{\text {add }}=8.5$ ), ${ }^{1,2}$ and a unimolecular reaction (estimated as $\log _{10} A_{\mathrm{f}}=13$ ), a fragmentation may be competitive only where there is a difference in the two activation barriers $\left(E_{\mathrm{A}, \mathrm{f}}-E_{\mathrm{A}, \mathrm{add}}\right)$ of less than 5-10 kcal/mol. The addition/fragmentation reactions of benzyl radical and alkenes fall outside of this range, suggesting that these reactions may be considered to good approximation irreversible. The addition of a 3-methyl group (as an analogue for a styrenic copolymerization) makes relatively little difference. On the other hand a degree of reversibility may be observable in a-substituted styrenic monomers containing resonance stabilizing groups $\left(-\mathrm{CN},-\mathrm{CH}=\mathrm{CH}_{2},-\mathrm{Ph} ; 3 \mathbf{e}-\mathbf{g}\right)$, particularly at low concentrations and relatively high temperatures. In a bulk polymerization, the high concentration of monomer favors the addition reaction.

\section{ASSOCIATED CONTENT}

S Supporting Information. Computational output in the form of optimized geometries, energies, and vibrational/ZPE corrections for species relevant to this study. This material is available free of charge via the Internet at http://pubs.acs.org.

\section{AUTHOR INFORMATION}

\section{Corresponding Author}

*E-mail: jspoole@bsu.edu.

\section{ACKNOWLEDGMENT}

JSP acknowledges financial support from the Research Corporation Cottrell College Science Award (CC-6456). Calculations were carried out on the BSU College of Sciences and Humanities Beowulf Cluster. MLC acknowledges support from the Australian Research Council under their Centres of Excellence program and generous allocations of supercomputing time on the National Facility of the Australian National Computational Infrastructure.

\section{REFERENCES}

(1) Walbiner, M.; Wu, J.-Q.; Fischer, H. Helv. Chim. Acta 1995, 78, 910 .

(2) Fischer, H.; Radom, L. Angew. Chem., Int. Ed. Engl. 2001, 40, 1340.
(3) Gasanov, R. G.; Vasil'eva, T. T.; Gapusenko, S. I.; Borisov, Y. A. Mendeleev Commun. 1991, 111.

(4) Kandanarachchi, P. H.; Autrey, T.; Franz, J. A. J. Org. Chem. 2002, 67, 7937.

(5) Aldabbagh, F.; Bowman, W. R.; Mann, E. Tetrahedron Lett. 1997, $38,7937$.

(6) Guindeuil, S.; Zard, S. Z. Chem. Commun. 2006, 665.

(7) Bacque, E.; El-Qacemi, M.; Zard, S. Z. Org. Lett. 2004, 6, 3671.

(8) (a) Ly, T.-M.; Quiclet-Sire, B.; Sortais, B.; Zard, S. Z. Tetrahedron Lett. 1999, 40, 2533. (b) Gagosz, F.; Zard, S. Z. Org. Lett. 2002, 4, 4345. (c) Quiclet-Sire, B.; Sortais, B.; Zard, S. Z. Chem. Commun. 2002, 1692.

(d) Moutrille, C.; Zard, S. Z. Tetrahedron Lett. 2004, 45, 4631.

(9) For examples, see(a) Cholleton, N.; Zard, S. Z. Tetrahedron Lett. 1998, 39, 7295. (b) Quiclet-Sire, B.; Zard, S. Z. Chem. Commun. 2002, 2306. (c) Cordero-Vargas, A.; Perez-Martin, I.; Quiclet-Sire, B.; Zard, S. Z. Org. Biomol. Chem. 2004, 2, 3018. (d) Cordero-Vargas, A.; Quiclet-Sire, B.; Zard, S. Z. Tetrahedron Lett. 2004, 45, 7335. (e) Binot, G.; Zard, S. Z. Tetrahedron Lett. 2005, 46, 7503.

(10) (a) Ohno, H.; Okumura, M.; Maeda, S.; Iwasaki, H.; Wakayama, R.; Tanaka, T. J. Org. Chem. 2003, 68, 7722. (b) Ohno, H.; Iwasaki, H.; Eguchi, T.; Tanaka, T. Chem. Commun. 2004, 2228. (c) Iwasaki, H.; Eguchi, T.; Tsutsui, N.; Ohno, H.; Tanaka, T. J. Org. Chem. 2008, 73, 7145.

(11) Leroi, C.; Bertin, D.; Dufils, P.-E.; Gigmes, D.; Marque, S.; Tordo, P.; Couturier, J.-L.; Guerret, O.; Ciufolini, M. A. Org. Lett. 2003, 5, 4943.

(12) For exampleStuder, A. Angew. Chem., Int. Ed. Engl. 2000, 39, 1108.

(13) (a) Wong, M. W.; Radom, L. J. Phys. Chem. 1995, 99, 8582. (b) Wong, M. W.; Radom, L. J. Phys. Chem. A 1998, 102, 2237.

(14) Henry, D. J.; Parkinson, C. J.; Radom, L. J. Phys. Chem. A 2002, 106, 7927.

(15) Mayer, P. M.; Parkinson, C. J.; Smith, D. M.; Radom, L. J. Chem. Phys. 1998, 108, 604.

(16) Gómez-Balderas, R.; Coote, M. L.; Henry, D. J.; Radom, L. J. Phys. Chem. A 2004, 108, 2874.

(17) Frisch, M. J.; Trucks, G. W.; Schlegel, H. B.; Scuseria, G. E.; Robb, M. A.; Cheeseman, J. R.; Montgomery, J. A., Jr.; Vreven, T.; Kudin, K. N.; Burant, J. C.; Millam, J. M.; Iyengar, S. S.; Tomasi, J.; Barone, V.; Mennucci, B.; Cossi, M.; Scalmani, G.; Rega, N.; Petersson, G. A.; Nakatsuji, H.; Hada, M.; Ehara, M.; Toyota, K.; Fukuda, R.; Hasegawa, J.; Ishida, M.; Nakajima, T.; Honda, Y.; Kitao, O.; Nakai, H.; Klene, M.; Li, X.; Knox, J. E.; Hratchian, H. P.; Cross, J. B.; Adamo, C.; Jaramillo, J.; Gomperts, R.; Stratmann, R. E.; Yazyev, O.; Austin, A. J.; Cammi, R.; Pomelli, C.; Ochterski, J. W.; Ayala, P. Y.; Morokuma, K.; Voth, G. A.; Salvador, P.; Dannenberg, J. J.; Zakrzewski, V. G.; Dapprich, S.; Daniels, A. D.; Strain, M. C.; Farkas, O.; Malick, D. K.; Rabuck, A. D.; Raghavachari, K.; Foresman, J. B.; Ortiz, J. V.; Cui, Q.; Baboul, A. G.; Clifford, S.; Cioslowski, J.; Stefanov, B. B.; Liu, G.; Liashenko, A.; Piskorz, P.; Komaromi, I.; Martin, R. L.; Fox, D. J.; Keith, T.; Al-Laham, M. A.; Peng, C. Y.; Nanayakkara, A.; Challacombe, M.; Gill, P. M. W.; Johnson, B.; Chen, W.; Wong, M. W.; Gonzalez, C.; Pople, J. A. Gaussian 03, Revision C.02; Gaussian, Inc.: Wallingford CT, 2004.

(18) (a) Becke, A. D. Phys. Rev. A 1988, 38, 3098. (b) Becke, A. D. J. Chem. Phys. 1993, 98, 5648. (c) Lee, C.; Yang, W.; Parr, R. G. Phys. Rev. $B$ 1988, 37, 785 .

(19) Scott, A. P.; Radom, L. J. Phys. Chem. 1996, 100, 16502.

(20) Izgorodina, E. I.; Brittain, D. R. B.; Hodgson, J. L.; Krenske, E. H.; Lin, C. Y.; Namazian, M.; Coote, M. L. J. Phys. Chem. A 2007, 111,10754 .

(21) Henry, D. J.; Sullivan, M. B.; Radom, L. J. Chem. Phys. 2003, $118,4849$.

(22) Coote, M. L.; Lin, C. Y.; Beckwith, A. L. J.; Zavitsas, A. A. Phys. Chem. Chem. Phys. 2010, 12, 9597.

(23) Lin, C. Y.; Hodgson, J. L.; Namazian, M.; Coote, M. L. J. Phys. Chem. A 2009, 113, 3690.

(24) (a) Lin, C. Y.; Izgorodina, E. I.; Coote, M. L. Macromolecules 2010, 43, 553. (b) Izgorodina, E. I.; Coote, M. L. Chem. Phys. 2006, 324, 96. 
(25) Lin, C. Y.; Izgorodina, E. I.; Coote, M. L. J. Phys. Chem. A 2008, $112,1956$.

(26) Truhlar, D. G. J. Comput. Chem. 1991, 12, 266.

(27) Pye, C. C.; Ziegler, T.; van Lenthe, E.; Louwen, J. N. Can. J. Chem. 2009, 87, 790.

(28) Louwen, J. N.; Pye, C.; Lenthe, E. v. ADF2008.01 COSMORS, SCM, Theoretical Chemistry; Vrije Universiteit: Amsterdam, The Netherlands, http://www.scm.com, 2008.

(29) (a) Reed, A. E.; Weinstock, R. B.; Weinhold, F. J. Chem. Phys. 1985, 83, 735. (b) Reed, A. E.; Weinhold, F.; Curtiss, J. A. Chem. Rev. $1988,88,899$.

(30) DeMatteo, M.; Poole, J. S.; Shi, X.; Sachdeva, R.; Hatcher, P. G.; Hadad, C. M.; Platz, M. S. J. Am. Chem. Soc. 2005, 127, 7094.

(31) Chernikova, E.; Golubev, V.; Filippov, A.; Lin, C. Y.; Coote, M. L. Polym. Chem. 2010, 1, 1437-1440.

(32) Semenov, N. N. Some Problems of Chemical Kinetics and Reactivity, Engl. Transl.; Pergamon Press: New York, 1958; Vol. 1.

(33) Tedder, J. M.; Walton, J. C. Acc. Chem. Res. 1976, 9, 183. 